\title{
$\underline{\mathrm{O} J \mathrm{ED}}$
}

Volume 5, Issue 1 (2020), pp. 89-93

International Journal of

Multidisciplinary Perspectives in Higher Education ISSN: 2474-2546 Print/ ISSN: 2474-2554 Online https://ojed.org/jimphe

\section{Ready, Fire, Aim: Adapting to COVID-19}

\section{Wade Smith}

Southeastern Louisiana University

\begin{abstract}
This paper provides insight into the rapid transition experienced by the students and staff who, before COVID-19, were part of a blended instructional format for their classes. The students reported general satisfaction with the online transition while expressing reservations about the loss of personal interaction and concerns about inabilities to engage field experiences deemed critical to completion of the program
\end{abstract}

Keywords: instructional preferences, student adaptability, student resilience

This past semester started in a normal and predictable fashion. It did not end that way. Normally students in our educational leadership courses engage a blended curriculum where some portions of the class are delivered online while also maintaining face-to-face instruction.

Instructional changes necessitated by COVID-19 were introduced with drastic swiftness. In Louisiana, where our college is located, the executive order announcing the closure of schools came with no prior notice. I have spoken with essential personnel who were on a conference call with the office of emergency preparedness one hour before the announcement and they were given no notice of what was about to be announced. When the executive order to close schools was enacted, my institution cancelled classes for one week in order to give students and staff alike a chance to get their bearings. Instructors were expected to use this interval to begin a transition to full-time, online delivery for the remainder of the semester. 


\section{Responding to the Crisis}

So, it began. During the week of class cancellation, instructors were expected to modify their original class schedules and to gear them towards full-time, online delivery. The expectations for course modifications were consistent for the entire university, but the strategies employed to reach these expectations were left to the discretion of the individual faculty members. Given the fact that no hints of immediate cessation of face-toface instruction was even being considered at the executive level of government, it is likely that instructor discretion in how change would be implemented was the only viable option for the university.

The change in instructional delivery required significant modification to classroom learning objectives. Each class in our program has a major project, known as an artifact, to complete. Regardless of the class, the artifact requires a significant amount of field-based work in the school where the degree candidate is working. For my particular cohorts, the class artifact focused on auditing the school's efforts to create equitable learning opportunities. Clearly, the expectations for the artifact were no longer tenable since K-12 schools were also required to transition to online instruction. In our class, we amended the artifact to become a check list that students could refer to when they assumed their first administrative position.

Besides significantly modifying the artifact's requirements, we also created six class goals to correspond with the remaining meetings. The goals were combinations of NELP standards that are embedded throughout our program delivery. Each class focused on a particular goal, and we reserved one class for a wrap-up and debrief for materials that had been covered. We also created three case studies that would directly apply to situations a first-year principal could expect to face.

Two separate cohorts undertook this revised learning plan. I had met one cohort for the first half of the semester, so we were able to interact faceto-face. The other cohort, however, had never met me. Historically in our program, students received their instruction entirely face-to-face or through a hybrid model where some course material was presented online synchronously or asynchronously. These students were now, for the first time, going to class completely in an online format. The first cohort, as mentioned, had met face-to-face earlier in the year. The second cohort, however, had never met me. This would be the first time any of these students would be taking a course with an instructor they had not met faceto-face.

As we began the classes an immediate problem arose; the students did not appear on the screen in our delivery platform. We resolved this problem after the first week of instruction by applying an add-on to the screen that allowed everyone to see everyone. If we had not found that option, it would have been much more difficult to interact productively. 
Since our class was now proceeding in a manner that no one had anticipated, I thought it would be useful to conduct a program evaluation. Students were able to anonymously answer a short survey that asked for their perception of instruction effectiveness for traditional learning versus online instruction.

Students were asked to use a seven-point sliding scale were 0-3 represented a preference for traditional learning, 4 indicated that traditional and online learning was viewed equally, and 5-7 represented a preference for online learning. Students were also asked to provide comments with two open-ended responses. An item analysis was conducted on the six items hypothesized to assess Instructional Preference. Each of the six items was correlated with the total score, with the item removed. All of the correlations were greater than 0.30 with a Cronbach's alpha of 0.89 indicating strong internal consistency.

Student means for their perceptions for each of the items are listed below:

a. Instruction pacing (4.47)

b. Interact with classmates, $(2.53)$

c. Ability to interact with instructor, (3.93)

d. Completing course requirements, (4.07)

e. Quality of feedback, (3.87)

f. Overall instructional effectiveness, (3.73)

Open-ended questions:

1. How could online instruction better serve you?

2. Any other thoughts on traditional or online instruction?

The program evaluation proved to be a valuable means of gathering insight from the students. Mean scores that were close to 4 for almost every item suggested the students perceived the rapidly implemented online format for instruction to be generally equivalent to what they would have expected from a traditional course format and this view was supported by informal conversations with students after the survey was completed. This was particularly encouraging, given the short preparation time available to make the changes that were necessary to move to a virtual learning environment. That said, the trend was noticeably absent for responses related to interacting with classmates. Clearly, students felt like the opportunity to interact with their peers was a strong suite of their past experiences. Students elaborated on this finding in their open-ended responses, repeatedly noting that the personal interactions that take place in face-to-face instruction were important to them and the inability to personally interact to the same degree in the virtual class environment detracted from their overall sense of course satisfaction.

Another consistent theme in the open-ended responses was the concerns raised by the inability to acquire field hours with all school campuses closes. Their concern is duly noted. How does one acquire field experiences when 
the "field" is not currently available? Rectifying this problem will be a priority as we move into the summer courses and alternative opportunities such as case studies that mimic the actual field experience are under development.

Given that we all, students and instructor alike, were propelled into our circumstances with little to no advanced warning, considerable effort was directed towards ensuring that students felt comfortable and they knew they were not working in isolation. Students were given my cellphone number and encouraged to use it. We also used a class debrief from each class where the high points were provided by me in a summation. Power point were designed so that students could interact with them in real time, and these power points were shared to everyone the next day.

It was heartening to have students comment favorably at the course's completion about how well the classes had gone. When students completed their anonymous course evaluations, the following comments were provided:

I got into this program to be a teacher leader. Not necessarily a principal, but someone to help new teachers rise to their potential That I might in fact be the right kind of something that would make a good principal was encouraging and has revived something in me that I wasn't even aware I had let die. I am finally ready to shine again, and it feels so good. Thank you for that. You did that for me. Your classes and the challenging but doable work did that for me. Thanks again.

Thanks for an awesome semester! I've learned a ton and look forward to applying what I've learned in the future.

Even though we had to shift gears, I thoroughly enjoyed the class. Our time together was both informative and fun. And fun was something I definitely looked forward to. Thanks again!

In the past I have shied away from using a virtual component to my classes. I have always preferred the conversations and interactions that come from being in the same room together. I learned that it is possible to replicate many of these advantages in a virtual classroom also. Student reactions during the class and the results of the survey we generated both provided reinforcement for this thinking, as did the comments provided during the students' course evaluations.

The obvious drawback to our situation was the inability for students to do any work at their schools. COVID-19 will not last forever, and eventually we will be able to return to normalcy. The knowledge gained during this semester has provided invaluable insight on how to merge the virtual world with field-based experiences. 
We are all familiar with the adage, Ready, Aim, Fire! It may be familiar, but it does not capture the reality of our response to COVID-19. We were not ready for an immediate shift to virtual learning, but we quickly got up to speed. We had to take what we had and immediately put it to use. In short, we had to fire. As we went through the class, we discovered how to not only make the best of our circumstances but also how to make our circumstances the best they could be. In this regard we were continually aiming. We quickly prepared for the transition to complete online instruction because it was our only option. For students and for myself it was surprisingly enjoyable, and the experiences during this very unusual semester should serve us all well.

\section{Author Bio}

Wade Smith, PhD, is an assistant professor in the school of educational leadership at Southeastern Louisiana University. His prior work experiences include nearly thirty years of school-based administration, including the roles of principal and superintendent. He has been appointed to serve as an expert on testing and assessment by the Governor's Office for the state of Louisiana. Major research interests include policy analysis, selfefficacy, and effective teaching and learning environments. Email: roy.smith@selu.edu 